\title{
Non-invasive approaches to monitor EGFR-TKI treatment in non-small-cell lung cancer
}

\author{
Wei Sun, Xun Yuan, Yijun Tian, Hua Wu, Hanxiao Xu, Guoqing Hu and Kongming Wu*
}

\begin{abstract}
Tyrosine kinase inhibitors of epidermal growth factor receptor (EGFR-TKIs) are standard treatments for advanced non-small-cell lung cancer (NSCLC) patients harboring activating epidermal growth factor receptor (EGFR) mutations. Nowadays, tumor tissues acquired by surgery or biopsy are the routine materials for EGFR mutation analysis. However, the accessibility of tumor tissues is not always satisfactory in advanced NSCLC. Moreover, a high proportion of NSCLC patients will eventually develop resistance to EGFR-TKIs. Invasive procedures, such as surgery or biopsy, are impractical to be performed repeatedly to assess the evolution of EGFR-TKI resistance. Thus, exploring some convenient and less invasive techniques to monitor EGFR-TKI treatment is urgently needed. Circulating cell-free tumor DNA (ctDNA) has a high degree of specificity to detect EGFR mutations in NSCLC. Besides, ctDNA is capable of monitoring the disease progression during EGFR-TKI treatment. Certain serum microRNAs that correlate with EGFR signaling pathway, such as miR-21 and miR-10b, have been demonstrated to be helpful in evaluating the efficiency of EGFR-TKI therapeutics. A commercialized serum-based proteomic test, named VeriStrat test, has shown an outstanding ability to predict the clinical outcome of NSCLC patients receiving EGFR-TKIs. Analysis of EGFR mutations in circulating tumor cells (CTCS) is feasible, and CTCs represent a promising material to predict EGFR-TKI-treatment efficacy and resistance. These evidences suggested that non-invasive techniques based on serum or plasma samples had a great potential for monitoring EGFR-TKI treatment in NSCLC. In this review, we summarized these non-invasive approaches and considered their possible applications in EGFR-TKI-treatment monitoring.
\end{abstract}

Keywords: Epidermal growth factor receptor, Tyrosine kinase inhibitors, Circulating cell-free tumor DNA, MicroRNAs, Proteomics, Circulating tumor cells, Non-small-cell lung cancer

\section{Introduction}

Lung cancer is the most commonly diagnosed cancer as well as the leading cause of cancer-related deaths [1]. Non-smallcell lung cancer (NSCLC) accounts for approximately $83 \%$ of all lung cancers, and nearly $80 \%$ of NSCLC patients are diagnosed with advanced or distant stages [2]. So far, the common cancer-driver genes identified in NSCLC include the mutant activations of Kirsten rat sarcoma (KRAS), epidermal growth factor receptor (EGFR), proto-oncogene B-Raf (BRAF), and phosphoinositide-3-kinase, catalytic, $\alpha$ polypeptide gene (PIK3CA) [3]. Several other molecular alterations, such as echinoderm microtubule-associated protein-like 4-anaplastic lymphoma kinase (EML4-ALK) fusion [4], Notch signaling activation [5, 6], and dysregulation

\footnotetext{
* Correspondence: gqhu@tjh.tjmu.edu.cn; kmwu@tjh.tjmu.edu.cn Department of Oncology, Tongji Hospital, Tongji Medical College, Huazhong University of Science and Technology, 1095 Jiefang Road, Wuhan 430030/, Hubei, People's Republic of China
}

(c) 2015 Sun et al. This is an Open Access article distributed under the terms of the Creative Commons Attribution License (http://creativecommons.org/licenses/by/4.0), which permits unrestricted use, distribution, and reproduction in any medium, provided the original work is properly credited. The Creative Commons Public Domain Dedication waiver (http:// creativecommons.org/publicdomain/Zero/1.0/) applies to the data made available in this article, unless otherwise stated. of the nucleo-cytoplasmic transport of proteins [7], also participate in NSCLC progression. Multiple small-molecule inhibitors directed at these molecular targets have been extensively developed, and some of them are migrating from bench to bedside [4, 7, 8]. However, despite these rapid progresses, tyrosine kinase inhibitors of epidermal growth factor receptor (EGFR-TKIs) are still the most successful example of targeted therapy in NSCLC. Compared with conventional chemotherapy, EGFR-TKIs can achieve prolonged progression-free survival (PFS) with reduced side effects in NSCLC patients harboring activating EGFR mutation [9].

Nowadays, EGFR gene mutations are the standard predictive biomarkers for selecting NSCLC patients to receive EGFR-TKI treatment. The point mutation in exon 21 (L858R) or deletion in exon 19 predicts good response to EGFR-TKIs [10], while the point mutation (T790M) in exon 20 implies resistance to EGFR-TKIs [11]. The 
routine materials for EGFR mutation analyses are tumor tissues acquired by surgery or biopsy. However, assessment of EGFR mutation status depending on tumor tissues has many limitations. First, the accessibility of tumor tissues is not always satisfactory. Most NSCLC patients are diagnosed with advanced or distant stages. Performing surgery or biopsy to obtain tissues from these patients is often impractical. Only $20 \%$ to $50 \%$ NSCLC patients could provide sufficient tissues to receive molecular analysis even in large well-designed clinical trials [9, 12-15]. Second, a high proportion of NSCLC patients will eventually develop EGFR-TKI resistance [16, 17]. Identifying a molecular mechanism of acquired resistance to EGFRTKIs and developing relevant targeted drugs are needed for effective second-line treatments $[18,19]$. But, assessing treatment resistance in real time by tumor tissues is not feasible as repeated surgery or biopsy is inappropriate in most patients. Furthermore, surgery and biopsy are not without clinical complications. The adverse event rates for thoracic biopsies were reported to be $17.1 \%$ [20]. Considering these limitations, exploring some convenient, economic, and less invasive techniques to monitor EGFR-TKI treatment in NSCLC is urgently needed.

Non-invasive approaches, usually based on plasma or serum samples, showed great potential for monitoring EGFR-TKI treatment in recent years. Circulating cell-free tumor DNA (ctDNA), which is released from tumor cells to circulating blood, can be applied to detect EGFR mutations in NSCLC patients [21-23]. Moreover, the dynamic changes in ctDNA EGFR mutation status could predict the clinical outcome of EGFR-TKI treatment [24]. MicroRNAs (miRNAs) are associated with tumor progression, suggesting their potential applications for treatment monitoring. Several serum miRNAs have been identified to associate with response to EGFR-TKIs in NSCLC [25, 26]. Circulating miRNAs may also act as potential non-invasive biomarkers to monitor EGFR-TKI treatment. Serum proteomics is an emerging science. Analyzing serum for specific proteins by mass spectrometry is becoming an important tool to identify biomarkers in cancers [27]. The VeriStrat test, a commercialized serum-based proteomic test, has emerged as a promising approach to predict the outcome of NSCLC patients receiving EGFR-TKIs [28-31]. Circulating tumor cells (CTCs) can be detected in the blood of many cancer patients and play an important role in metastasis. Several studies have demonstrated that EGFR mutation status in CTCs matches well with that in tumor tissues [32-34]. Isolating DNA from CTCs to receive EGFR mutation analysis may be another effective way to monitor EGFR-TKI treatment.

In summary, serum ctDNA, miRNAs, proteomic biomarkers, and CTCs can be obtained non-invasively, making them ideal substitutes for tumor tissues (Fig. 1). In addition, these liquid biopsies can be performed multiple times and allow for dynamic detection of molecular changes in tumor cells. Hereby, we summarized these noninvasive approaches in this review and considered their possible applications in monitoring EGFR-TKI treatment.

\section{Circulating cell-free tumor DNA (ctDNA)}

Cancer-associated genetic alterations, such as point mutations, deletions, copy number variations, and methylation patterns, can be detected in ctDNA [35, 36]. In NSCLC, ctDNA shows a high diagnostic accuracy for EGFR mutation analyses. Moreover, serum ctDNA analysis could effectively predict the efficacy of EGFR-TKI treatment and identify the molecular changes associated with EGFR-TKI resistance.

\section{Detection of EGFR gene mutations}

When ctDNA is used to analyze gene mutations in NSCLC patients, one vital issue is whether the genetic variation within blood was consistent with tumor tissues. Table 1 summarizes studies which detected EGFR mutations in NSCLC patients using ctDNA. As shown, a wide range of diagnostic accuracy values were reported. The sensitivities for ctDNA ranged from $17.1 \%$ [23] to $100 \%[37,38]$, while the specificities were from $71.4 \%$ [39] to $100 \%$ [23, 37, 40-47]. Additionally, the concordance rates between ctDNA and tumor tissues showed a big variation, ranging from $27.5 \%$ [23] to $100 \%$ [37]. The large variability among various studies might be caused by different laboratory procedures and techniques utilized for quantification of ctDNA. Besides, the big difference in the numbers of patients might also influence the reported sensitivity and specificity. To address these issues, two recent meta-analyses were performed $[48,49]$. Their main purposes were to compare ctDNA with tumor tissues in terms of its diagnostic accuracy for the detection of EGFR mutations. Both of their results revealed that ctDNA had high diagnostic accuracy for the detection of EGFR mutations in NSCLC. The pooled sensitivities for ctDNA in these two meta-analyses were reported to be $67.4 \%$ and $62 \%$, respectively. And the specificities for ctDNA were $93.5 \%$ and $95.9 \%$, respectively. These evidences suggested that assessment of EGFR mutations by ctDNA has adequate diagnostic accuracy, especially the high degree of specificity. Thus, ctDNA is a highly specific and effective biomarker for EGFR mutation analyses. Future standard techniques for detecting EGFR mutations in ctDNA might validate its clinical value in NSCLC patients.

\section{Prediction of EGFR-TKI-treatment efficacy}

Regarding the clinical application of ctDNA, another important issue is whether ctDNA is capable of predicting EGFR-TKI-treatment efficacy. Indeed, several studies have analyzed the association between pre-treatment ctDNA 


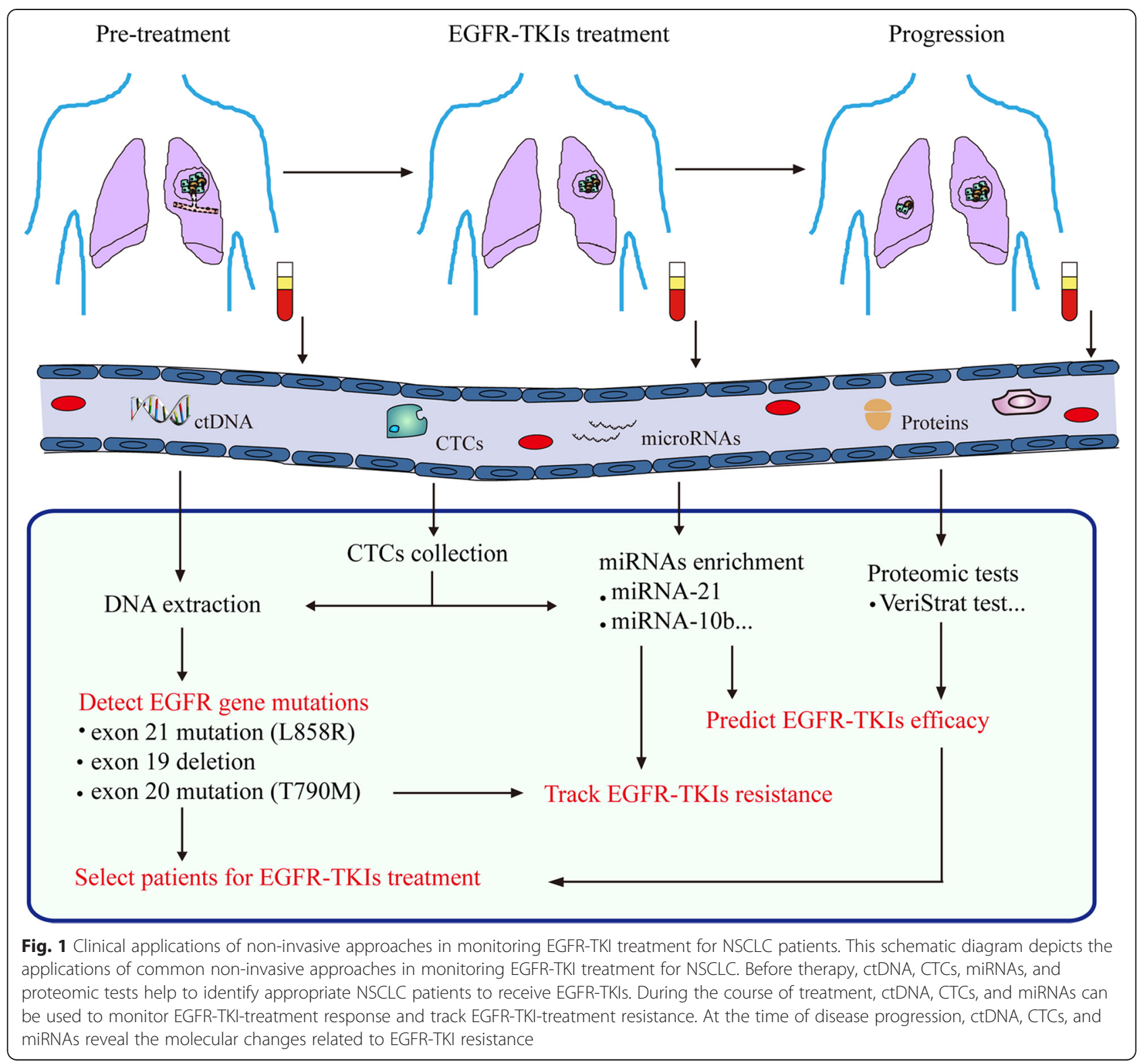

EGFR mutation status and clinical outcomes. Goto et al. [40] evaluated EGFR mutations in ctDNA from patients in the IPASS study recruited in Japan (IPASS, The IRESSA Pan-Asia Study). A significant correlation between ctDNA EGFR mutation status and PFS was founded in this study. PFS was significantly longer with gefitinib than carboplatin/paclitaxel in the activating ctDNA EGFR mutation subgroup (hazard ratio (HR), 0.29; $95 \%$ confidence interval (CI), 0.14-0.60). Another large-scale research also demonstrated that EGFR mutation status in ctDNA was a good predictor for PFS after EGFR-TKI therapy (mutant versus wild-type: 10.1 versus 3.7 months, $p=0.038$ ) [50]. Recently, the predictive value of the dynamic changes in
ctDNA EGFR mutation status during therapy was explored by a prospective study [24]. In this study, patients were randomized to receive six cycles of gemcitabine/platinum plus sequential erlotinib or placebo. Blood samples at baseline, cycle 3 , and progression were assessed. In patients with ctDNA-based EGFR mutation-positive status at baseline, those that transformed to EGFR mutationnegative status had better PFS and overall survival (OS) than those with detectable EGFR mutations at cycle 3. These data suggested that dynamic changes of EGFR status in ctDNA were able to predict the benefit of EGFRTKI treatment. In conclusion, ctDNA EGFR mutation test has a good ability to predict EGFR-TKI-treatment efficacy, 
Table 1 EGFR mutations detected in ctDNA of NSCLC patients

\begin{tabular}{|c|c|c|c|c|c|c|}
\hline Authors & Case number & Method & Positive (\%) & Sensitivity (\%) & Specificity (\%) & Concordance (\%) \\
\hline$\overline{\text { Sun } H[21]}$ & 55 & MST-PCR & 18.2 & NM & NM & NM \\
\hline Douillard JY [22] & 784 & ARMS & 10.5 & 65.7 & 99.8 & 94.3 \\
\hline Kim HR [23] & 40 & PNA-PCR & 15 & 17.1 & 100 & 27.5 \\
\hline Punnoose EA [37] & 24 & DxS kits & 16.7 & 100 & 100 & 100 \\
\hline Goto K [40] & 194 & DxS Kits + ARMS & 23.7 & 43 & 100 & 66.3 \\
\hline Jian G [81] & 56 & RT-PCR & 23.2 & NM & NM & NM \\
\hline He C [38] & 134 & ME-PCR & 49.3 & 100 & 90 & 94.4 \\
\hline Zhang L [82] & 627 & ME-PCR & 22 & NM & NM & NM \\
\hline Zhao X [83] & 111 & ME-PCR + sequencing & 17.1 & 35.6 & 95.5 & 71.2 \\
\hline Kimura H [39] & 27 & $P C R+$ sequencing & 37 & 75 & 71.4 & NM \\
\hline Kim ST [84] & 57 & PNA-LNA PCR & 19.3 & 66.7 & 93.3 & 87.7 \\
\hline Bai H [85] & 230 & DHPLC & 34.3 & 81.8 & 89.5 & 74 \\
\hline Yung TK [41] & 35 & Digital PCR & 43 & 92 & 100 & NM \\
\hline Mack PC [42] & 49 & DxS kits & 20.4 & 66.7 & 100 & NM \\
\hline Kuang Y [86] & 54 & ARMS & 47 & 70 & 85 & NM \\
\hline Kimura H [87] & 42 & ARMS & 16.7 & 75 & 97.1 & 92.9 \\
\hline Kimura H [88] & 27 & ARMS & 48.1 & 50 & 85.7 & 72.7 \\
\hline Brevet M [89] & 31 & ME-PCR + sequencing & 58.1 & 38.9 & 84.6 & NM \\
\hline Jiang B [43] & 58 & ME-PCR + sequencing & 24.1 & 77.8 & 100 & 93.1 \\
\hline Wang S [90] & 134 & ARMS & 12.7 & 22.1 & 97 & 59 \\
\hline Jing CW [91] & 120 & HRM & 25.8 & 64.4 & 97.3 & 85 \\
\hline Zhang H [44] & 86 & MEL & 17.4 & 68.2 & 100 & 91.9 \\
\hline Liu X [45] & 86 & ARMS & 31.4 & 67.5 & 100 & 84.9 \\
\hline Xu F [46] & 34 & ARMS & 11.8 & 50 & 100 & 88.2 \\
\hline Huang Z [92] & 822 & DHPLC & 32.7 & 63.5 & 84.6 & 77 \\
\hline Sriram KB [47] & 64 & ME-PCR & 4.7 & 50 & 100 & 95.3 \\
\hline Weber B [50] & 196 & cobas $^{\oplus}$ EGFR test & 11.7 & 60.7 & 96.4 & 91.3 \\
\hline
\end{tabular}

MST mutant-specific primers with a Taqman probe, $P C R$ polymerase chain reaction, $A R M S$ the amplification refractory mutation system, $P N A-P C R$ peptide nucleic-acid-mediated PCR, DxS kits DxS EGFR Mutation Test Kit (DxS, Manchester, UK), RT-PCR real-time PCR, ME-PCR mutant-enriched PCR, PNA-LNA PCR the peptide nucleic-acid-locked nucleic acid PCR, DHPLC denaturing high-performance liquid chromatography, HRM high-resolution melting analysis, MEL mutant-enriched liquidchip, NM not mentioned

and it may be a reliable approach to guide EGFR-TKI treatments for NSCLC patients.

\section{Tracking molecular changes related to EGFR-TKI resistance}

In NSCLC, despite an initial response, resistance to EGFR-TKIs will occur and thereafter tumor progresses. For this reason, identification of the molecular mechanisms of EGFR-TKI resistance is needed. Several mechanisms responsible for EGFR-TKI acquired resistance have been described, including the second T790M mutation of EGFR, amplification of MET or HER2, and mutations of PIK3CA or BRAF [51, 52]. The second T790M mutation of EGFR accounts for half of the TKI-resistant cases, and monitoring T790M mutation is useful for the estimate of EGFR-TKI resistance. Taniguchi et al. performed a study to quantitatively detect the T790M-resistant mutations in ctDNA [53]. In $43.5 \%(10 / 23)$ of patients who had progressive disease after EGFR-TKI treatment, the T790M mutation in ctDNA was detected. Another study also proved that sequencing of plasma DNA could complement current invasive approaches to identify mutations associated with acquired drug resistance in advanced cancers [36]. This study tracked the genomic evolution during therapy in various kinds of cancer patients by the sequencing of cancer exomes in serial plasma samples. It revealed that the EGFR T790M mutation in plasma could be detected at progression, but not at the start of treatment 
in NSCLC patients treated with gefitinib. These results suggested that ctDNA was capable of monitoring disease progression during EGFR-TKI therapy.

\section{MicroRNAs}

MicroRNAs (miRNAs) play critical roles in tumor development, including tumor initiation, invasion, and metastasis [54-56]. Several miRNAs that correlate with the EGFR signaling pathway have been demonstrated to mediate EGFRTKI resistance in NSCLC [57-60]. Moreover, circulating miRNAs are emerging as promising biomarkers and therapeutic targets for many cancers [61-65]. Many studies have shown that changes in circulating miRNAs during treatment are predictive of tumor response [63, 66, 67]. Circulating microRNAs may have the potential to be developed into next-generation biomarkers for cancer screening. In NSCLC patients, certain miRNAs have been detected in the serum samples. These circulating miRNAs are showing their potential in EGFR-TKI-treatment monitoring [25, 26].

Shen et al. performed a study to identify the miRNA panel in the serum of NSCLC patients with different EGFR mutation status [26]. They revealed that the expressions of serum miR-21 and miR-10b were much higher in patients with EGFR mutation than those without mutation. In addition, patients with up-regulated miR-21 expression had a shorter OS time, suggesting that miR-21 expression may be a reliable predictor for gefitinib-treatment efficacy. Furthermore, the levels of miR-10b expression in progressive patients were significantly higher than those in nonmetastatic patients. These results suggested that the expression of circulating miRNAs differed between patients with positive and negative EGFR mutation status and the levels of circulating miRNAs are associated with response to EGFR-TKI therapy.

Another study, which aimed to investigate the role of miR-21 in the acquired resistance to EGFR-TKIs, showed that miR-21 can mediate EGFR-TKI resistance by downregulating PTEN and PDCD4 and activating the PI3K/Akt pathway [25]. Besides, it revealed that the serum miR-21 expression in NSCLC patients receiving EGFR-TKIs was much higher at the time of acquired resistance than that at baseline. These evidences indicated that circulating miR-21 might act as an available biomarker to monitor the acquired resistance to EGFR-TKIs.

The above available evidences suggested that serum miR21 and miR-10b were helpful for monitoring EGFR-TKI treatment. Future data may update these results and validate the practical utility of circulating miRNAs in NSCLC.

\section{Proteomic biomarkers}

Similar to other high-throughput technologies, proteomics are able to detect multiple proteins that are expressed as a cause or consequence of ongoing diseases [68]. Proteomic profiles of various specimens obtained from cancer patients are expected to increase our understanding of tumor pathogenesis and cancer therapy. In the management of NSCLC, proteomic profiles have been shown to be useful in disease detection, diagnosis, treatment, and prognostication [69]. Recent studies revealed that a simple serumbased proteomic test had a great potential for selecting NSCLC patients to receive EGFR-TKI treatment [28-31].

Taguchi and his colleagues reported a mass spectrometry serum test which was able to identify a subset of NSCLC patients with better outcomes after EGFR-TKI therapy in 2007 [28]. Then this test was commercialized under the name of VeriStrat and applied in multiple clinical trials. This novel test used the integrated intensities of eight mass spectral peaks and classified patients into VeriStrat "good" and VeriStrat "poor" statuses. Several subsequent studies also demonstrated that VeriStrat "good" patients could benefit more from EGFR-TKI therapy than "poor" ones [29-31, 70, 71]. Additionally, a large meta-analysis based on these studies confirmed that the VeriStrat "good" status predicted a better clinical outcome with a pooled HR of 0.40 (95\% CI, 0.32 to $0.49 ; p=0.000$ ) for OS and 0.49 (95\% CI, 0.39 to $0.60 ; p=0.000$ ) for PFS [72]. Furthermore, the original study has tested the concordance of mass spectrometry generated by two independent institutions [28]. Their results indicated that the VeriStrat test had an outstanding reproducibility. Thus, the VeriStrat test might be a potential tool to predict the clinical outcome of NSCLC patients after treatment with EGFR-TKIs.

The PROSE trial, the first prospective, randomized proteomic stratified phase III study, was designed to evaluate the predictive value of the VeriStrat test on the outcome in advanced NSCLC patients treated with either EGFR-TKIs or standard chemotherapy [73]. Information provided by this trial suggested that this proteomic test is predictive of OS benefit for erlotinib and chemotherapy. Patients with a VeriStrat "poor" status had worse survival on erlotinib than on chemotherapy (HR, 1.72; $95 \% \mathrm{CI}, 1.08-2.74 ; p=0.022$ ). Chemotherapy is likely to result in improved outcomes for patients with a VeriStrat "poor" status. This trial complemented the results of previous retrospective studies and helped to identify the subgroup of NSCLC patients who may not benefit from EGFR-TKIs.

In this emerging field, the number of studies is relatively limited but growing. Another phase III study (EMPHASIS) was opened for advanced squamous cell NSCLC (Clinicaltrials.gov identifier: NCT01652469). Patients with relapsed squamous cell lung cancer are assigned to two groups (VeriStrat "good" and VeriStrat "poor") and then randomized between EGFR-TKI (erlotinib) and chemotherapy (docetaxel). One of its goals is to explore the predictive and prognostic ability of the VeriStrat test signature. In addition, a clinical trial that aims to measure whether VeriStrat could be a biomarker of benefit from treatment with standard chemotherapy regimens in first-line NSCLC patients is 
currently recruiting participants (Clinicaltrials.gov identifier: NCT02055144). These ongoing trials may prospectively validate the predictive role of this serum-based proteomic test in NSCLC patients.

\section{Circulating tumor cells}

Circulating tumor cells (CTCs), which are disseminated from tumor tissues, have the potential to complement tumor tissues for tumor characterization and cancertreatment monitoring [74]. Various kinds of genetic abnormalities, such as KRAS mutation [75], EGFR mutation [32, 33], and ALK rearrangement [76-78], have been identified in CTCs from NSCLC patients. Moreover, CTCs represent promising materials for EGFR-TKI-treatment monitoring.

\section{Detection of EGFR gene mutations}

The EGFR gene mutation profiles of CTCs in NSCLC have been analyzed by several studies. Recently, a study investigated the EGFR mutations in CTCs by coupling the CellSearch System with next-generation sequencing (NGS) [32]. In 37 advanced NSCLC patients harboring activating EGFR mutations in tumor tissues, 31 cases were identified to have the EGFR mutations in CTCs. Additionally, $94 \%$ (29/31) of the mutation types detected by NGS on CTCs were in accordance with that found in matched tumor tissues. These data suggested that CTCs represented a suitable source for detection of EGFR mutations. Another study developed an available method to detect EGFR mutations in single CTC [33]. The laser cell microdissection (LCM) technique was used to isolate individual CTCs. Then it was followed by the whole-genome amplification of DNA for exon 19 deletion and L858R and T790M mutation detection. Ninety-five percent (19/20) of the single CTC underwent PCR amplicons for at least one of the three mutation sites. The amplification success rates were $55 \%(11 / 20)$ for exon 19 deletion, $45 \%$ (9/20) for T790M, and $85 \%(17 / 20)$ for L858R. These results suggested that detecting EGFR mutations in CTCs was feasible. CTCs may be available materials for the detection of EGFR mutations in NSCLC.

\section{Monitoring EGFR-TKI-treatment efficacy}

As mentioned above, the dynamic changes in ctDNA-based EGFR status are able to predict the benefit of EGFR-TKI treatment [24]. Similarly, EGFR mutation status in CTCs can be another biomarker for monitoring EGFR-TKItreatment efficacy. Breitenbuecher et al. adopted an assay based on real-time polymerase chain reaction and melting curve analysis to detect activating EGFR mutations in CTCs [34]. All CTCs in baseline blood samples from eight NSCLC patients were found to harbor the EGFR mutations that corresponded with tumor tissues. During treatment, sequential samples from four of eight patients turned "negative" for EGFR mutations. These four patients who "cleared" EGFR-mutant CTCs achieved disease control, with three partial responses (PRs) and one stable disease (SD). In the remaining four patients with persisting EGFRmutant CTCs, only one had PR. In addition, patients who had "cleared" EGFR-mutant CTCs showed a significantly longer recurrence-free time when compared with patients whose EGFR mutations in CTCs remained "positive" (median time, 355 versus 116 days). With the follow-up time extending, all four patients with "cleared" EGFR-mutant CTCs developed progressive disease. Interestingly, EGFR mutation status in CTCs from these four patients returned to "positive" prior to clinical progression. Thus, an increase in EGFR-mutant CTC counts might be an early indicator for disease relapse and EGFR-TKI resistance. Moreover, changes in CTC levels were also capable of predicting the outcome of EGFR-TKI treatment. Punnoose et al. performed a study to evaluate the utility of CTCs in NSCLC patients treated with pertuzumab and erlotinib [37]. Their results revealed that decreased CTC counts upon treatment were associated with better response and longer PFS. Thus,

Table 2 Summary of non-invasive approaches to monitor EGFR-TKI treatment in NSCLC patients

\begin{tabular}{|c|c|c|c|c|c|c|}
\hline $\begin{array}{l}\text { Non-invasive } \\
\text { approaches }\end{array}$ & Methods & Sensitivity & Specificity & Advantages & Disadvantages & Cost \\
\hline ctDNA & $\begin{array}{l}\text { PCR-based techniques; } \\
\text { DNA sequencing }\end{array}$ & Moderate & High & $\begin{array}{l}\text { Feasible on small-amount samples; } \\
\text { suitable for detecting specific genes; } \\
\text { high reproducibility }\end{array}$ & Normalization problems & Low \\
\hline MicroRNAs & RT-PCR-based techniques & Moderate & High & $\begin{array}{l}\text { Feasible on small-amount samples; } \\
\text { rapid and low cost; high reproducibility }\end{array}$ & $\begin{array}{l}\text { Normalization problems; } \\
\text { indirect evidence; few } \\
\text { correlative studies }\end{array}$ & Low \\
\hline $\begin{array}{l}\text { Proteomic } \\
\text { biomarkers }\end{array}$ & Mass spectrometry & High & Moderate & $\begin{array}{l}\text { Feasible on small-amount samples; } \\
\text { suitable for detecting specific proteins }\end{array}$ & $\begin{array}{l}\text { Normalization problems; } \\
\text { complex tumor proteins } \\
\text { profile; indirect evidence }\end{array}$ & Moderate \\
\hline CTCs & $\begin{array}{l}\text { Cell enrichment techniques } \\
+ \text { PCR-based techniques or } \\
\text { DNA sequencing }\end{array}$ & High & High & $\begin{array}{l}\text { Able to analyze distinct cell } \\
\text { subpopulations; suitable for } \\
\text { detecting specific genes }\end{array}$ & $\begin{array}{l}\text { Low frequency; dependent } \\
\text { on capture techniques; } \\
\text { normalization problems }\end{array}$ & High \\
\hline
\end{tabular}


CTCs are effective to monitor EGFR-TKI-treatment efficacy in NSCLC patients.

\section{Tracking emergence of EGFR-TKI resistance}

DNA extracted from CTCs, like other sources of DNA, has been shown to be an effective material for the detection of the T790M mutation of EGFR in NSCLC. Maheswaran et al. performed an EGFR mutation analysis on CTCs in NSCLC patients treated with EGFR-TKIs [79]. T790M mutation was detected in CTCs from 9 of 14 patients (64 \%) who had clinical progression. This finding was consistent with the reported prevalence of T790M (about $50 \%$ ) [80]. Hence, CTCs collected during treatment might provide a potential alternative for EGFRTKI-resistance analysis. Future large-scaled prospective studies may verify the practical utility of CTCs in EGFR-TKI-treatment monitoring.

\section{Conclusions}

Non-invasive approaches, usually based on serum or plasma samples, are showing great potential to monitor EGFR-TKI treatment in NSCLC (Fig. 1 and Table 2). ctDNA has a high degree of specificity to detect EGFR mutations. Moreover, ctDNA is capable of monitoring disease progression during EGFR-TKI treatment. Certain serum microRNAs, such as miR-21 and miR-10b, can effectively predict the EGFR-TKI-treatment efficacy and resistance. The VeriStrat test has been proved to be helpful for selecting NSCLC patients to receive EGFR-TKIs. CTCs are feasible for EGFR mutation analysis and represent promising materials to monitor EGFR-TKI treatment. Thus, these liquid specimens can complement with tumor tissues and help to guide EGFR-TKI therapy in NSCLC. As numerous high-throughput detection techniques are being developed extensively, liquid samples obtained by non-invasive approaches possess great potential to be valuable materials applied for guiding individual treatment. However, several hurdles should be overcome before applying these approaches into routine clinical practice (Table 2). One of the most important issues is the lack of consensus in technical approaches. Future standard and universal techniques for these non-invasive approaches may validate their applications in monitoring EGFR-TKI treatment in NSCLC.

\section{Competing interests}

The authors declare that they have no competing interests.

\section{Authors' contributions}

WS, XY, and YT searched literatures and prepared the manuscript. HW and $\mathrm{HX}$ collected the data and revised the manuscript. GH and KW designed the study and wrote the manuscript. All authors had read and approved the final manuscript.

\section{Acknowledgements}

This work was supported by National Natural Science Foundation of China (Grant No. 81172422, 81261120395, 8157102025, and 81272491).
Received: 14 June 2015 Accepted: 20 July 2015

Published online: 31 July 2015

\section{References}

1. Torre LA, Bray F, Siegel RL, Ferlay J, Lortet-Tieulent J, Jemal A. Global cancer statistics, 2012. CA Cancer J Clin. 2015;65(2):87-108.

2. Howlader N, Noone AM, Krapcho M, Garshell J, Miller D, Altekruse SF, et al. SEER cancer statistics review, 1975-2012. National Cancer Institute. Bethesda, MD, http://seer.cancer.gov/csr/1975_2012/, based on November 2014 SEER data submission, posted to the SEER web site, April 2015

3. Farago AF, Snyder EL, Jacks T. SnapShot: lung cancer models. Cell. 2012;149(1):246-6. e241.

4. Iragavarapu C, Mustafa M, Akinleye A, Furqan M, Mittal V, Cang S, et al. Novel ALK inhibitors in clinical use and development. J Hematol Oncol. 2015:8(1):17.

5. Yuan X, Wu H, Han N, Xu H, Chu Q, Yu S, et al. Notch signaling and EMT in non-small cell lung cancer: biological significance and therapeutic application. J Hematol Oncol. 2014;7(1):87.

6. Yuan $X, W u H, X u H, H a n N, C h u$ Q, Yu S, et al. Meta-analysis reveals the correlation of Notch signaling with non-small cell lung cancer progression and prognosis. Sci Rep. 2015;5:10338.

7. Parikh K, Cang S, Sekhri A, Liu D. Selective inhibitors of nuclear export (SINE)-a novel class of anti-cancer agents. J Hematol Oncol. 2014;7:78.

8. Gravina GL, Senapedis W, McCauley D, Baloglu E, Shacham S, Festuccia C. Nucleo-cytoplasmic transport as a therapeutic target of cancer. J Hematol Oncol. 2014;7:85.

9. Fukuoka M, Wu YL, Thongprasert S, Sunpaweravong P, Leong SS, Sriuranpong $\mathrm{V}$, et al. Biomarker analyses and final overall survival results from a phase III, randomized, open-label, first-line study of gefitinib versus carboplatin/paclitaxel in clinically selected patients with advanced nonsmall-cell lung cancer in Asia (IPASS). J Clin Oncol. 2011;29(21):2866-74.

10. Sharma SV, Bell DW, Settleman J, Haber DA. Epidermal growth factor receptor mutations in lung cancer. Nat Rev Cancer. 2007;7(3):169-81.

11. Engelman JA, Mukohara T, Zejnullahu K, Lifshits E, Borras AM, Gale CM, et al. Allelic dilution obscures detection of a biologically significant resistance mutation in EGFR-amplified lung cancer. J Clin Invest. 2006;116(10):2695-706.

12. Tsao MS, Sakurada A, Cutz JC, Zhu CQ, Kamel-Reid S, Squire J, et al. Erlotinib in lung cancer - molecular and clinical predictors of outcome. New Engl J Med. 2005:353(2):133-44.

13. Hirsch FR, Varella-Garcia M, Bunn Jr PA, Franklin WA, Dziadziuszko R, Thatcher $\mathrm{N}$, et al. Molecular predictors of outcome with gefitinib in a phase III placebo-controlled study in advanced non-small-cell lung cancer. J Clin Oncol. 2006;24(31):5034-42.

14. Douillard JY, Shepherd FA, Hirsh V, Mok T, Socinski MA, Gervais R, et al. Molecular predictors of outcome with gefitinib and docetaxel in previously treated non-small-cell lung cancer: data from the randomized phase III INTEREST trial. J Clin Oncol. 2010;28(5):744-52.

15. Brugger W, Triller N, Blasinska-Morawiec M, Curescu S, Sakalauskas R, Manikhas GM, et al. Prospective molecular marker analyses of EGFR and KRAS from a randomized, placebo-controlled study of erlotinib maintenance therapy in advanced non-small-cell lung cancer. J Clin Oncol. 2011;29(31):4113-20.

16. Janne PA. Challenges of detecting EGFR T790M in gefitinib/erlotinibresistant tumours. Lung Cancer. 2008;60 Suppl 2:S3-9.

17. Niu FY, WU YL. Novel agents and strategies for overcoming EGFR TKIs resistance. Exp Hematol Oncol. 2014;3(1):2.

18. Smith AD, Roda D, Yap TA. Strategies for modern biomarker and drug development in oncology. J Hematol Oncol. 2014;7(1):70.

19. Zhang J, Cao J, Li J, Zhang Y, Chen Z, Peng W, et al. A phase I study of AST1306, a novel irreversible EGFR and HER2 kinase inhibitor, in patients with advanced solid tumors. J Hematol Oncol. 2014;7:22.

20. Overman MJ, Modak J, Kopetz S, Murthy R, Yao JC, Hicks ME, et al. Use of research biopsies in clinical trials: are risks and benefits adequately discussed? J Clin Oncol. 2013;31(1):17-22.

21. Sun H, Gan ZC, Gao JJ, Zheng F. Non-invasive detection of EGFR deletion at exon 19 in non-small cell lung cancer by real time diagnostic. Clin Lab. 2014;60(9):1517-26.

22. Douillard JY, Ostoros G, Cobo M, Ciuleanu T, Cole R, McWalter G, et al. Gefitinib treatment in EGFR mutated caucasian NSCLC: circulating-free tumor DNA as a surrogate for determination of EGFR status. J Thorac Oncol. 2014;9(9):1345-53. 
23. Kim HR, Lee SY, Hyun DS, Lee MK, Lee HK, Choi CM, et al. Detection of EGFR mutations in circulating free DNA by PNA-mediated PCR clamping. J Exp Clin Cancer Res. 2013;32(1):50.

24. Mok T, Wu YL, Lee JS, Yu CJ, Sriuranpong V, Sandoval-Tan J, et al. Detection and dynamic changes of EGFR mutations from circulating tumor DNA as a predictor of survival outcomes in NSCLC patients treated with first-line intercalated erlotinib and chemotherapy. Clin Cancer Res. 2015 [Epub ahead of print].

25. Li B, Ren S, Li X, Wang Y, Garfield D, Zhou S, et al. MiR-21 overexpression is associated with acquired resistance of EGFR-TKI in non-small cell lung cancer. Lung Cancer. 2014;83(2):146-53.

26. Shen $Y$, Tang D, Yao R, Wang M, Wang $Y$, Yao $Y$, et al. MicroRNA expression profiles associated with survival, disease progression, and response to gefitinib in completely resected non-small-cell lung cancer with EGFR mutation. Med Oncol. 2013;30(4):750.

27. Indovina P, Marcelli E, Maranta P, Tarro G. Lung cancer proteomics: recent advances in biomarker discovery. Int J Proteomics. 2011;2011:726869.

28. Taguchi F, Solomon B, Gregorc V, Roder H, Gray R, Kasahara K, et al. Mass spectrometry to classify non-small-cell lung cancer patients for clinical outcome after treatment with epidermal growth factor receptor tyrosine kinase inhibitors: a multicohort cross-institutional study. J Natl Cancer Inst. 2007;99(11):838-46.

29. Carbone DP, Salmon JS, Billheimer D, Chen H, Sandler A, Roder $\mathrm{H}$, et al. VeriStrat classifier for survival and time to progression in non-small cell lung cancer (NSCLC) patients treated with erlotinib and bevacizumab. Lung Cancer. 2010;69(3):337-40.

30. Kuiper JL, Lind JS, Groen HJ, Roder J, Grigorieva J, Roder H, et al, VeriStrat((R)) has prognostic value in advanced stage NSCLC patients treated with erlotinib and sorafenib. Br J Cancer. 2012;107(11):1820-5.

31. Gautschi O, Dingemans AM, Crowe S, Peters S, Roder H, Grigorieva J, et al. VeriStrat(R) has a prognostic value for patients with advanced non-small cell lung cancer treated with erlotinib and bevacizumab in the first line: pooled analysis of SAKK19/05 and NTR528. Lung Cancer. 2013;79(1):59-64.

32. Marchetti A, Del Grammastro M, Felicioni L, Malatesta S, Filice G, Centi I, et al. Assessment of EGFR mutations in circulating tumor cell preparations from NSCLC patients by next generation sequencing: toward a real-time liquid biopsy for treatment. PLoS One. 2014;9(8), e103883.

33. Ran R, Li L, Wang M, Wang S, Zheng Z, Lin PP. Determination of EGFR mutations in single cells microdissected from enriched lung tumor cells in peripheral blood. Anal Bioanal Chem. 2013;405(23):7377-82

34. Breitenbuecher F, Hoffarth S, Worm K, Cortes-Incio D, Gauler TC, Kohler J, et al. Development of a highly sensitive and specific method for detection of circulating tumor cells harboring somatic mutations in non-small-cell lung cancer patients. PLoS One. 2014;9(1), e85350.

35. Nie K, Jia Y, Zhang X. Cell-free circulating tumor DNA in plasma/serum of non-small cell lung cancer. Tumour Biol. 2015;36(1):7-19.

36. Murtaza M, Dawson SJ, Tsui DW, Gale D, Forshew T, Piskorz AM, et al. Noninvasive analysis of acquired resistance to cancer therapy by sequencing of plasma DNA. Nature. 2013;497(7447):108-12.

37. Punnoose EA, Atwal S, Liu W, Raja R, Fine BM, Hughes BG, et al. Evaluation of circulating tumor cells and circulating tumor DNA in non-small cell lung cancer: association with clinical endpoints in a phase II clinical trial of pertuzumab and erlotinib. Clin Cancer Res. 2012;18(8):2391-401.

38. He C, Liu M, Zhou C, Zhang J, Ouyang M, Zhong N, et al. Detection of epidermal growth factor receptor mutations in plasma by mutant-enriched PCR assay for prediction of the response to gefitinib in patients with non-small-cell lung cancer. Int J Cancer. 2009;125(10):2393-9.

39. Kimura H, Kasahara K, Shibata K, Sone T, Yoshimoto A, Kita T, et al. EGFR mutation of tumor and serum in gefitinib-treated patients with chemotherapy-naive non-small cell lung cancer. J Thorac Oncol. 2006;1(3):260-7.

40. Goto K, Ichinose Y, Ohe Y, Yamamoto N, Negoro S, Nishio K, et al. Epidermal growth factor receptor mutation status in circulating free DNA in serum: from IPASS, a phase III study of gefitinib or carboplatin/paclitaxel in nonsmall cell lung cancer. J Thorac Oncol. 2012;7(1):115-21.

41. Yung TK, Chan KC, Mok TS, Tong J, To KF, Lo YM. Single-molecule detection of epidermal growth factor receptor mutations in plasma by microfluidics digital PCR in non-small cell lung cancer patients. Clin Cancer Res. 2009;15(6):2076-84.

42. Mack PC, Holland WS, Burich RA, Sangha R, Solis LJ, Li Y, et al. EGFR mutations detected in plasma are associated with patient outcomes in erlotinib plus docetaxel-treated non-small cell lung cancer. J Thorac Oncol. 2009;4(12):1466-72.
43. Jiang B, Liu F, Yang L, Zhang W, Yuan H, Wang J, et al. Serum detection of epidermal growth factor receptor gene mutations using mutant-enriched sequencing in Chinese patients with advanced non-small cell lung cancer. J Int Med Res. 2011;39(4):1392-401.

44. Zhang H, Liu D, Li S, Zheng Y, Yang X, Li X, et al. Comparison of EGFR signaling pathway somatic DNA mutations derived from peripheral blood and corresponding tumor tissue of patients with advanced non-small-cell lung cancer using liquidchip technology. J Mol Diagn. 2013;15(6):819-26.

45. Liu X, Lu Y, Zhu G, Lei Y, Zheng L, Qin H, et al. The diagnostic accuracy of pleural effusion and plasma samples versus tumour tissue for detection of EGFR mutation in patients with advanced non-small cell lung cancer: comparison of methodologies. J Clin Pathol. 2013;66(12):1065-9.

46. Xu F, Wu J, Xue C, Zhao Y, Jiang W, Lin L, et al. Comparison of different methods for detecting epidermal growth factor receptor mutations in peripheral blood and tumor tissue of non-small cell lung cancer as a predictor of response to gefitinib. Onco Targets Ther. 2012;5:439-47.

47. Sriram KB, Tan ME, Savarimuthu SM, Wright CM, Relan V, Stockwell RE, et al. Screening for activating EGFR mutations in surgically resected nonsmall cell lung cancer. Eur Respir J. 2011;38(4):903-10.

48. Qiu M, Wang J, Xu Y, Ding X, Li M, Jiang F, et al. Circulating tumor DNA is effective for the detection of EGFR mutation in non-small cell lung cancer: a meta-analysis. Cancer Epidemiol Biomarkers Prev. 2015;24(1):206-12.

49. Luo J, Shen L, Zheng D. Diagnostic value of circulating free DNA for the detection of EGFR mutation status in NSCLC: a systematic review and meta-analysis. Sci Rep. 2014;4:6269.

50. Weber B, Meldgaard P, Hager H, Wu L, Wei W, Tsai J, et al. Detection of EGFR mutations in plasma and biopsies from non-small cell lung cancer patients by allele-specific PCR assays. BMC Cancer. 2014;14:294.

51. Wood SL, Pernemalm M, Crosbie PA, Whetton AD. Molecular histology of lung cancer: from targets to treatments. Cancer Treat Rev. 2015;41(4):361-75.

52. Del Re M, Vasile E, Falcone A, Danesi R, Petrini I. Molecular analysis of cellfree circulating DNA for the diagnosis of somatic mutations associated with resistance to tyrosine kinase inhibitors in non-small-cell lung cancer. Expert Rev Mol Diagn. 2014;14(4):453-68.

53. Taniguchi K, Uchida J, Nishino K, Kumagai T, Okuyama T, Okami J, et al. Quantitative detection of EGFR mutations in circulating tumor DNA derived from lung adenocarcinomas. Clin Cancer Res. 2011;17(24):7808-15.

54. Cortinovis D, Monica V, Pietrantonio F, Ceresoli GL, La Spina CM, Wannesson L. MicroRNAs in non-small cell lung cancer: current status and future therapeutic promises. Curr Pharm Des. 2014;20(24):3982-90.

55. Kim M, Slack FJ. MicroRNA-mediated regulation of KRAS in cancer. J Hematol Oncol. 2014:7(1):84.

56. Chai ZT, Zhu XD, Ao JY, Wang WQ, Gao DM, Kong J, et al. MicroRNA-26a suppresses recruitment of macrophages by down-regulating macrophage colony-stimulating factor expression through the PI3K Akt pathway in hepatocellular carcinoma. J Hematol Oncol. 2015;8(1):56.

57. Shen H, Zhu F, Liu J, Xu T, Pei D, Wang R, et al. Alteration in Mir-21/PTEN expression modulates gefitinib resistance in non-small cell lung cancer. PLoS One. 2014;9(7), e103305.

58. Wang F, Chan LW, Law HK, Cho WC, Tang P, Yu J, et al. Exploring microRNA-mediated alteration of EGFR signaling pathway in non-small cell lung cancer using an mRNA:miRNA regression model supported by target prediction databases. Genomics. 2014;104(6):504-11.

59. Zhou JY, Chen X, Zhao J, Bao Z, Chen X, Zhang P, et al. MicroRNA-34a overcomes HGF-mediated gefitinib resistance in EGFR mutant lung cancer cells partly by targeting MET. Cancer Lett. 2014;351(2):265-71.

60. Ahmad A, Maitah MY, Ginnebaugh KR, Li Y, Bao B, Gadgeel SM, et al. Inhibition of Hedgehog signaling sensitizes NSCLC cells to standard therapies through modulation of EMT-regulating miRNAs. J Hematol Oncol. 2013;6(1):77.

61. Hou B, Ishinaga H, Midorikawa K, Shah SA, Nakamura S, Hiraku Y, et al. Circulating microRNAs as novel prognosis biomarkers for head and neck squamous cell carcinoma. Cancer Biol Ther. 2015;16(7):1042-6.

62. Khoury S, Tran N. Circulating microRNAs: potential biomarkers for common malignancies. Biomark Med. 2015;9(2):131-51.

63. Hansen TF, Carlsen AL, Heegaard NH, Sorensen FB, Jakobsen A. Changes in circulating microRNA-126 during treatment with chemotherapy and bevacizumab predicts treatment response in patients with metastatic colorectal cancer. Br J Cancer. 2015;112(4):624-9.

64. Wang WT, Chen YQ. Circulating miRNAs in cancer: from detection to therapy. J Hematol Oncol. 2014;7(1):86. 
65. Wang WT, Zhao YN, Yan JX, Weng MY, Wang Y, Chen YQ, et al. Differentially expressed microRNAs in the serum of cervical squamous cell carcinoma patients before and after surgery. J Hematol Oncol. 2014;7:6.

66. Summerer I, Niyazi M, Unger K, Pitea A, Zangen V, Hess J, et al. Changes in circulating microRNAs after radiochemotherapy in head and neck cancer patients. Radiat Oncol. 2013:8:296.

67. Jones K, Nourse JP, Keane C, Bhatnagar A, Gandhi MK. Plasma microRNA are disease response biomarkers in classical Hodgkin lymphoma. Clin Cancer Res. 2014;20(1):253-64.

68. Sallam RM. Proteomics in cancer biomarkers discovery: challenges and applications. Dis Markers. 2015;2015:321370.

69. Tanvetyanon T, Creelan BC, Chiappori AA. Current clinical application of genomic and proteomic profiling in non-small-cell lung cancer. Cancer Control. 2014;21(1):32-9.

70. Akerley W, Boucher K, Rich N, Egbert L, Harker G, Bylund J, et al. A phase II study of bevacizumab and erlotinib as initial treatment for metastatic non-squamous, non-small cell lung cancer with serum proteomic evaluation. Lung Cancer. 2013;79(3):307-11.

71. Stinchcombe TE, Roder J, Peterman AH, Grigorieva J, Lee CB, Moore DT, et al. A retrospective analysis of VeriStrat status on outcome of a randomized phase II trial of first-line therapy with gemcitabine, erlotinib, or the combination in elderly patients (age 70 years or older) with stage IIIB/IV non-small-cell lung cancer. J Thorac Oncol. 2013;8(4):443-51.

72. Sun W, Hu G, Long G, Wang J, Liu D, Hu G. Predictive value of a serumbased proteomic test in non-small-cell lung cancer patients treated with epidermal growth factor receptor tyrosine kinase inhibitors: a meta-analysis. Curr Med Res Opin. 2014;30(10):2033-9.

73. Gregorc V, Novello S, Lazzari C, Barni S, Aieta M, Mencoboni M, et al. Predictive value of a proteomic signature in patients with non-small-cell lung cancer treated with second-line erlotinib or chemotherapy (PROSE): a biomarker-stratified, randomised phase 3 trial. Lancet Oncol. 2014;15(7):713-21.

74. Lianidou ES, Strati A, Markou A. Circulating tumor cells as promising novel biomarkers in solid cancers. Crit Rev Clin Lab Sci. 2014;51(3):160-71.

75. Tsao DA, Yang MJ, Chang HJ, Yen LC, Chiu HH, Hsueh EJ, et al. A fast and convenient new technique to detect the therapeutic target, K-ras mutant, from peripheral blood in non-small cell lung cancer patients. Lung Cancer. 2010;68(1):51-7.

76. Faugeroux V, Pailler E, Auger N, Taylor M, Farace F. Clinical utility of circulating tumor cells in ALK-positive non-small-cell lung cancer. Front Oncol. 2014;4:281.

77. Pailler E, Adam J, Barthelemy A, Oulhen M, Auger N, Valent A, et al. Detection of circulating tumor cells harboring a unique ALK rearrangement in ALK-positive non-small-cell lung cancer. J Clin Oncol. 2013;31(18):2273-81.

78. Ilie M, Long E, Butori C, Hofman V, Coelle C, Mauro V, et al. ALK-gene rearrangement: a comparative analysis on circulating tumour cells and tumour tissue from patients with lung adenocarcinoma. Ann Oncol. 2012;23(11):2907-13.

79. Maheswaran S, Sequist LV, Nagrath S, Ulkus L, Brannigan B, Collura CV, et al. Detection of mutations in EGFR in circulating lung-cancer cells. N Engl J Med. 2008;359(4):366-77.

80. Pao W, Miller VA, Politi KA, Riely GJ, Somwar R, Zakowski MF, et al. Acquired resistance of lung adenocarcinomas to gefitinib or erlotinib is associated with a second mutation in the EGFR kinase domain. PLoS Med. 2005;2(3), e73.

81. Jian G, Songwen Z, Ling Z, Qinfang D, Jie Z, Liang T, et al. Prediction of epidermal growth factor receptor mutations in the plasma/pleural effusion to efficacy of gefitinib treatment in advanced non-small cell lung cancer. J Cancer Res Clin Oncol. 2010;136(9):1341-7.

82. Zhang L, Yang H, Zhao Y, Liu W, Wu S, He J, et al. Detection of EGFR somatic mutations in non-small cell lung cancer (NSCLC) using a novel mutant-enriched liquidchip (MEL) technology. Curr Drug Metab. 2012;13(7):1007-11.

83. Zhao X, Han RB, Zhao J, Wang J, Yang F, Zhong W, et al. Comparison of epidermal growth factor receptor mutation statuses in tissue and plasma in stage I-IV non-small cell lung cancer patients. Respiration. 2013;85(2):119-25.

84. Kim ST, Jung HY, Sung JS, Jo UH, Tanaka T, Hagiwara K, et al. Can serum be used for analyzing the EGFR mutation status in patients with advanced non-small cell lung cancer? Am J Clin Oncol. 2013;36(1):57-63.

85. Bai H, Mao L, Wang HS, Zhao J, Yang L, An T, et al. Epidermal growth factor receptor mutations in plasma DNA samples predict tumor response in Chinese patients with stages IIIB to IV non-small-cell lung cancer. J Clin Oncol. 2009;27(16):2653-9.

86. Kuang Y, Rogers A, Yeap BY, Wang L, Makrigiorgos M, Vetrand K, et al. Noninvasive detection of EGFR T790M in gefitinib or erlotinib resistant non-small cell lung cancer. Clin Cancer Res. 2009;15(8):2630-6.

87. Kimura H, Suminoe M, Kasahara K, Sone T, Araya T, Tamori S, et al. Evaluation of epidermal growth factor receptor mutation status in serum DNA as a predictor of response to gefitinib (IRESSA). Br J Cancer. 2007;97(6):778-84.

88. Kimura H, Kasahara K, Kawaishi M, Kunitoh H, Tamura T, Holloway B, et al. Detection of epidermal growth factor receptor mutations in serum as a predictor of the response to gefitinib in patients with non-small-cell lung cancer. Clin Cancer Res. 2006;12(13):3915-21.

89. Brevet M, Johnson ML, Azzoli CG, Ladanyi M. Detection of EGFR mutations in plasma DNA from lung cancer patients by mass spectrometry genotyping is predictive of tumor EGFR status and response to EGFR inhibitors. Lung Cancer. 2011;73(1):96-102.

90. Wang S, Han X, Hu X, Wang X, Zhao L, Tang L, et al. Clinical significance of pretreatment plasma biomarkers in advanced non-small cell lung cancer patients. Clin Chim Acta. 2014;430:63-70.

91. Jing CW, Wang Z, Cao HX, Ma R, Wu JZ. High resolution melting analysis for epidermal growth factor receptor mutations in formalin-fixed paraffin-embedded tissue and plasma free DNA from non-small cell lung cancer patients. Asian Pac J Cancer Prev. 2014;14(11):6619-23.

92. Huang Z, Wang Z, Bai H, Wu M, An T, Zhao J, et al. The detection of EGFR mutation status in plasma is reproducible and can dynamically predict the efficacy of EGFR-TKI. Thorac Cancer. 2012;3:334-40.

\section{Submit your next manuscript to BioMed Central and take full advantage of:}

- Convenient online submission

- Thorough peer review

- No space constraints or color figure charges

- Immediate publication on acceptance

- Inclusion in PubMed, CAS, Scopus and Google Scholar

- Research which is freely available for redistribution 